Here now is B-, who presents a less marked and less inveterate case of hysteria, but still one belonging to the order of hystero-epilepsy. She has been hemianresthetic and subject to major atticks for three years. 'This patient was affected with right hemianasthesia, and, at the simme time, as is the rule, with right ovarie. She presented in a marked degree all the classic phases of the attack-epileptoid period, contortions, "passional" attitudes, final delirium. The patient wiss submitted to the internal use of copper in July last. Under its influence the anosthesia and the fits have quite disappeared. The extemal applications of copper, which formerly threw the patient into that particular state which I have described to you, are now without any action on her. Is the cure complete, definitive? From all that precedes, I am inclined to think it is. Has it been produced by the action of copper? I leave it to you to decide.

Here is another patient sensitive to gold. I have known her to be hemiancesthetic in the left side for the last six years. As usual, she had left ovarie, and very marked hystero-epileptic fits. She was subjected to treatment with gold at the same date and in the same mamer as our first patient. At present she has but very rare attacks. Hemianzesthesia never manifests itself but temporarily, for a few hours, and only after the attacks. The application of gold on the left side of the body causes a recurrence of what I call the phenomena of " metallic anrsthesia."

The patient I now show you is $\mathrm{B}$ - in whom you have been able to study a most striking example of hysteric contracture. She has been diseased the last eleven years. She is affected with two distinct diseases, hystero-epilepsy (hysteria major) and real epilepsy. It is the combination which is usually called "hystero-epilepsy with distinct attacks." The internal administration of gold has produced no modification in her epilepsy. But it is not so with the symptoms of hystero-epilepsy. After the administration of gold, exhibited in the same mammer as in the preceding cases, hemianæsthisia, which for the last eleven years had persisted, has disappeared, and the hystero-epileptic fits, which were very frequent and complete, have now become very rare. Yet they exist, and have survived anxsthesia; consequently the patient is still, in a somewhat marked degree, under the influence of the diathesis. The other day she had a fit, after which supervened contracture. But the contracture lasted only seven or eight days, whereas before the treatment it generally lasted one or two months. I will add that the anresthesia, which formerly occupied the whole of the right side of the body, has shown itself after this attach only in the right lower limb, where the contracture had first developed itself

These are the four patients that $I$ had to show you. I leave these facts to your own appreciation. As to myself, I shall content myself with briefly drawing this conclusion, that the question is deserving of careful investigation.

Before concluding I must state that you may meet with cases, though rarely, in which hysteric patients are not sensitive to any known metal. I must also add that in the patients I have presented to you, and in whom a metallic idiosyncrasy has been found, the application of the suitable metal is without any effect when it is made at the time of the great attacks, or, if the word can be used, of the hysteric tides. You must choose a period of calm, in order that the action of the metals may be brought out in full relief.

Such are the principal phenomena of metalloscopy and metallo-therapy which I wished to bring before you. I am desirous, however, to acquaint you with an episode which is not wholly irrelevant to the principal subject of this lecture, though it is not connected with hysteria.

Hysteric hemianresthesia is not the only form of hemianæesthesia which may be modified by appropriate metallic applications, contrary to what Trousseau may have believed formerly, and to what Dr. Burq himself believed even quite recently. This has been shown by the results obtained in two of our patients affected with cerebral hemianresthesia (I mean with involvement of the superior senses-vision and smell), consequent upon an organic lesion of the brain, which had produced simultaneously post-hemiplegic hemichorea. In those two patients the insensibility was absolute, and dated eleven years in one ( $\left.\mathrm{R}_{-}\right)$, and in the other from her infancy, or about fifteen years $(\mathrm{P} \longrightarrow)$. A metallic application of iron in $\mathrm{R}$ - and of gold in $\mathrm{P}$ - has had the result of rapid and complete re-establishment of general and special sensibility. This result has not been altered for fifteen montlss, when the applications were commenced. may just remark that in neither of these patients there exists the slightest trace of an hysteric diathesis. One is a woman of fifty-five, very ealon, allimst anathetic. 'The other is aged twenty-four, and is much more docile thian the majority of patients of her age in my warls.

One word more before concluding. I wish to refer to the attempts made to eluciclate the whysical fitet which must be the condition of the physiologicel action of metals. In the first place, M. Regnard las shown the important fact that extremely weak currents of electricity produce exactly the same effects as metallic applications. However, it would be, perhaps, inaccurate to draw the conchusion that metallic applications exert an action by determining currents. Such is the opinion of M. Romain Vigouronx, who has conducted a series of experiments upon the sulject, and has deduced therefrom quite a reguliur theory of metallo-therapic phenomena. But I have no time to dwell longer upon a subject in connexion with which, besides, nothing definite has been yet done.

\section{ON THE MYDRIATIC PROPERTIES OF DUBOISIA MYOPOROIDES.}

BY JOHN TWEEDY, F.R.C.S.,

CLINTCAL ASSISTANT AT TIIN ROY II, LONDON OPHTHALAIC HOSPITAL

\section{WITH AN ACCOUNT OF ITS GENERAL PHYSIOLOGICAL} iC'TION.

BY SYDNEY RINGER, M.D.,

PROFESSOR OF THERIPELTICS AT ENIVERSITY COLLEGE, AND PHYSICLN TO CNIVERSTY COLLEGE HOSPITIL, LONDOS.

Is the carly part of December last I received from my friend, Dr. G. Forteseue, of Sydney, a small quantity of extract of Duboisia myonoroides, an indigenous tall shrub, growing plentifully in the forest lauds of Eastern Australia, and supposed to belong to the order Scrophulariaces. Dr. Fortescue having learnt first from Dr. Juseph Bancroft, of Brisbane, and, sulssequently, from his own observation, that the extract, when locally applied to the eye, is a powerful and rapid pupil-dilator and paralyser of the accommodation, was kind enough to suggest that I should make some experiments, similar to those which I recorded in THE LANCET of Jume 9th, 1877, on (xelsemina. Without delay, therefore, I began the experiments upon the eye, but as I was told that the physiological properties of duboisia were unknown, I was glad to share the extract I had received with Dr. Syrtney Ringer, who undertook to discover these properties by means of physiological experimentation upon the lower animals, and then upon man. I shall first give Dr. Ringer's report, and then add an account of my own observations.

I may here remark that last week $I$ had the pleasure of making the acquaintance of Dr. Joseph Bancroft, at present on a visit to this country, who told me that he had related the circumstances under which he came to discover the mydriatic proporties of duboisia, in a paper read before the Queensland Philosophical Society last October. I have thought it proper to appeud a brief summary of Dr. Bancroft's interesting paper.

REPORT ON THE PHYSIOLOGICAL ACTION OF DUBOISIA MYOPOROIDES, BY DR. SYDNEY RINGER.

Wishing to know something of the botanical relations of duboisia, I wrote to Professor Oliver, of Kew, who informed. me that "Duboisia belongs to the group of Salpiglossidex, which occupy a position intermediate between Solanaceæ and Scrophulariacese. Now however, it is definitively referred to Solanacese, notwithstanding its (duboisia's) didynamous stamens. It is indigenous in New South Wales, Queensland, and New Caledonia."

This information naturally suggested that its alkaloid is probably similar, if not identical, with atropia. My inves* tigations confirm this surmise. 'Thus I find that, like atropia, duboisia dilates the pupil, dries the mouth, arrests the secretion of the skin, produces headache and drowsiness. It also antagonises the effect of muscarin on the heart, and after 
some days excites tetanus in frogs. $\Lambda$ s the frug came with an established reputation as a pupil dilator, I was content to make only two or three confirmatory observations.

I next tested its action on a large Cyprus cat, injecting six minims of an aqueous solution of the extract ( 1 in 5 ) under the skin of the back. In fifteen mimutes the pujils began to dilate, and in twenty minutes they were very widely dilated and quite unaffected by light. The mouth also began to get dry in fifteen minutes, and in twenty minutes it became quite dry, so thit the cat's cry was very feeble. This was the only effect of the drug, with the exception perhaps of slight general weakness. Forty-one hours after the injection the mouth was still rather dry and the pupils still dilated, though less widely.

I then tested its action on two men, injecting subcutaneously half a grain and one grain respectively, and obtained marked physiological effects, most marked with the larger dose. In both the pupils became widely dilated and the mouth dry. After the larger dose the man's throat became so dry that he could scarcely speak. The dryness lasted five hours. Both men became rather sleepy in about fifteen minutes after the injection, the drowsiness lasting about two hours. The man with the larger dose complained of some general weakness, and both men suffered from headache, lasting about three hours. After the larger dose the pulse rose from 66 to 120 per minute.

These observations therefore proved that, whether topically applied or administered internally, duboisia dilates the pupil. Given internally, it also greatly dries the mouth, quickens the pulse, causes some muscular weakness, drowsiness, and headache-the same symptoms that follow atropia.

The next point to determine was whether duboisia, like atropia, wonld check perspiration. Accordingly I injected onethird of a grain of nitrate of pilocarpine (jaborandi) under the skin of a patient with non-febrile phthisis. In three minutes his face flushed, and perspiration and salivation began. In four minutes the perspiration was so free that beads of sweat stood upon the face. Nine minutes after the pilocarpine I injected three minims of the solution of extract of duboisia $(1$ in 4$)$-i.e., three-quarters of a grain. Seven minutes after this injection the skin was quite dry, and the mouth less moist. In ten minutes the man complained of dryness of the mouth, and the pupils began to dilate. In twentyfive minutes the tongue was quite dry at the end. At this time he was sleepy. Next morning - that is, nineteen hours after the experiment - the mouth was still a little dry and the pupils dilated. This experiment, therefore, proved that duboisia checks perspiration, and it confirms the previous conchusion that it dries the mouth and dilates the pupils.

I next tested whether, like atropia, duboisia antagonises the action of muscarin on the frow's heart. I divided the spinal cord of three froos opposite the occipito-atlantal membrane, and passed a pen into the cavity of the skull, destroying the brain, and at the same time preventing hremorhage. I then exposed the heart of these brainless frogs, and applied to the auricles and sinus venosus a small quantity of an alcoholic extract of amanita muscaria (muscarin), given me by Dr. Michael Foster. In the first experiment, in four minutes after the application of muscarin, the heart beats fell from 31 to 6 per minute. I then applied a minute quantity of extract of duboisia ( 1 in 2 ). In thirty seconds the beats rose to 28 per minute, and greatly increased in force. Ten hours after the heart still beat well at 40 per minute.

In the second experiment, the effects of the muscarin were ilifferent. As is sometimes the case, instead of slowing the heart, it affected the frequency very slightly, but weakened the strength of the contractions very considerably. Thus, after the application of musearin the heart's beats fell from 34 to 26 , and at last beat so feebly that the pulsations could only just be seen by careful examination with an oblique light. At this time I applied to the auricles and sinus a small quantity of extract of duboisia. In one minute the beats were stronger, and in fon the heart beat excellently at 30 per minute. Five hoves afterwards it still contracted vigorously at $2 t$

In the third experiment, the musearin reduced the beats from 32 to 14 , and made them. so weak that only the slightest detectable movement remained. I then added a small quantity of extract of duboisia, and at first all contraction ceased; but in two minutes the heart was very distinctly heating, and in three minutes it was contracting normally at 30 per minute. In five hours' time it beat feebly at 26.
These experiments show that, like atropia, extract of duboisia antidotes the action of muscarin on the frog's heart.

In still another respect duboisia acts like atropia. On Jan. 15th I injected hypodermically four minims of a solntion of the extract ( 1 in 2) into a frog weighing thirty grammes. This produeed some general weakness, from which the animal recovered. In forty-eight hours I found the animal slightly tetanic-that is to say, its movements were rather stiff, and when tapped in the back all the limbs were slightly jerked and then became stiff, and the toes were widely expanded. To prevent the tetanus becoming painful, I then divided the cord and destroyed the brain. I injected two other frogs with the same proportionate dose, but produced no tetanus. It is interesting to observe that whilst duboisia is, as it were, on the outskirts of the order Solanacer, and has many affinities with scrophulariaceous plants, its active principle, if not identical with, is very similar to, atropia.

It will be seen from Dr. Ringer's elaborate report that the physiological action of the extract of duboisia is apparently identical with that of atropia. The same remark applies to the effects of the local application to the eye. If there be any difference, it is that duboisia is more prompt and cnergetic than atropia, and certainly very much more so than the strongest extract of belladonna. Wishing to observe the effect of the undiluted extract, I placed a small portion of it on the conjunctiva of the lower lid of a damaged eye (Dec. 14th). Severe smarting and profuse lachrymation immediately followed, but scarcely any congestion of the conjunctival vessels. The smarting passed off in two or three minutes, but the lachrymation continued for about a'quarter of an hour. In ten minutes the pupil was dilated, but not fully, although it did not get larger afterwards. The accommodation was also greatly impaired, but to what extent I could not determine.

After this the extract was diluted with twenty parts of distilled water. This solution seemed to produce more rapid and complete dilatation than the undiluted extract, and did not cause smarting and but little watering of the eyes. The resulting dilatation of the pupil usually lasted from six to ten days, and the concomitant paralysis of accommodation, which in every instance became rapidly complete, about three or four days; it then gradually subsided, so that about five to seven days after the application the accommodation was as strong and active as before. The pupil in all cases was affected sooner and recovered later than the accommodation.

Having satisfied myself that the extract is a quick and powerful pupil-dilator, I wished to ascertain more clearly the rate and amount of its action upon the accommodation, and for this purpose I determined to use my own eye. I first carefully tested the state of vision, and found that I conld read No. 11 of Snellen's type distinctly from 4 in. (nearest point) to 21 in. (farthest point) and $V=\frac{20}{20}$. I then placed a single drop of a solution of the extract ( 1 in 20) within the lids of the tested eye. A little lachrymation followed, but no smarting. Exactly ten minutes afterwards the pupil began to dilate, and the sight became rather misty for near objects. When once started, dilatation proceeded very rapidly, so that fifteen minutes after instillation the pupil was widely dilated, and the nearest point had receded to $10 \mathrm{in}$. In twenty-five minutes $1 \frac{1}{2}$ Snellen could not be read at any distance by the unaided eye, and the accommodation was therefore, for all practical purposes, completely paralysed. By more elaborate tests I discovered that the effect of the extract went on increasing for four hours, when it attained its maximum. Twenty-four hours afterwards there was no appreciable amelioration, either in the pupil or in the accommodation, but within the next twenty four hours the effects began to pass rapidly off, so that fortyeight hours after the instillation I could see $1 \frac{1}{2}$ Snellen from $5 \frac{1}{2}$ in. to 21 in., although the pupil was not much smaller. In seventy-two hours, by an effort of accommodation, $1 \frac{1}{2}$ Snellen could be seen at $4 \frac{1}{2}$ in., and the pupil was rather smaller, and reacted slightly to light. From this time the accommodation becane stronger and more active every hour, and the pupil gradually diminished until it reached its natural size. Four days after the application the accommodation was restored, and three days later the pupil was active, and of its normal size.

I could not at any time detect any change in the actual or relative strength of the extra-ocular muscles.

Experience having shown that the application of the 
extract was not likely to be harmful to the eye, I resolved to employ it in all cases in which atropine was indicated. I have therefore used it largely in injuries and diseases of the cornea, in iritis, in spasm of accommodation, and whenever it has been necessary to paralyse the accommodation. Its action has in all instances been beneficial, and in some cases I have been tempted to believe superior to that of atropia.

Subjoined is a bricf account of Dr. Bancroft's experiments with extract of Duboisia myoporoides, which he was led to employ at the suggestion of Baron von Mueller, for the elucidation of some investigations on "pituri," a stimulating narcotic chewed by the natives of Central Australia. Pituri is, it may be observed, now referred to Baron Mueller's Duboisia Hopwoodii.

Dr. Bancroft found the effects of the subcutaneous injection of the duboisia extract on dogs and cats were as follows:- "Dogs and cats walk about in a helpless, blind manner, falling over the least irregularity of surface, and struggle, in the case of the dog, to get through and over all sorts of impassable obstacles. If let alone they go to sleep. They seem blind, or nearly so, with a widely dilated pupil." Some of the fluid extract, applied locally to the eye, caused wide dilatation of the pupil in a few minutes. The mydriatic properties of the duboisia extract were confirmed by Dr. Thomson, of the Brisbane Hospital ; by Dr. McIntosh, of the Ipswich Hospital ; and by Dr. Fortescue, of Sydney. The latter gentleman found that, after two drops of watery extract of duboisia had been instilled into a healthy eye, the pupil was widely dilated in ten minutes, and the accommodation completely paralysed in thirty minutes. "Four days after instillation the effect of accommodation had practically gone off, though a considerable mydriasis remained, and some slight dazzling and uncertainty of vision for three or four days longer."

Dr. Bancroft states that he has given duboisia in asthma and in photophobia. In man, he says, it causes much dilatation of the pupil and indistinctness of vision, also confusion of intellect, particularly at night, a thirsty dryness of the throat, and loss of taste.

Harley-street.

\section{SOME}

\section{STATISTICS OF ANTISEPTIC OPERATIONS IN THE YEAR 1877.}

BY RICHARD BARWELL, F.R.C.S.E., SURgEON TO CHARING-CROSS HOSPITAL.

THE whole theory of bacterial influence on organic matter, as also the very term contagium vivum, contain subjects of so much importance from almost every point of view, that even those persons least interested in scientific investigations must have felt that a doctrine of vast influence in economic, social, and sanitary matters had here become opened out. But more especially in my own study-that of surgery-does this teaching seen of such paramount import. ance that clear ideas upon the subject and its bearings in all directions ought as soon as possible to be attained. One of the clearest expressions on certain essential points was given in the address of Dr. Rolerts at the Manchester meeting of the British Medical $\Lambda$ ssociation-thus: "Organic matter hess no inherent power of generating bacteria, and no inherent power of passing into decomposition. Bacteric are the actual agents of decomposition. Bracteria one their origin to parent germs derived from survounding fuids."

These theorems, directly deducible from carefully planned experiments, carried on by a number of thoroughly trained and excellent observers, appear to me as well proven as any facts in the whole range of science. But we must nevertheless remember on what a very limited form of organic fluid these experiments have been made-viz., upon liquids which contain in suspension or solution, or both, organic matter, not only dead, but in which every trace of life, every germ capable of setting up organic action, has by the most minntely careful procedures been rigidly excluded. The experiments, then, render certain that organic matter thus treated cannot undergo a peculiar change until life-spores be added from without. But they prove nothing in regard to living organic fluids containing, as all such fluids do, innumerable cells, nuclei, and germs. Therefore such experiments leave us in absolute doubt as to whether organic tissue, fluid or solid, undergoing interstitial death or other change, is absolutely dependent for power of zymosis or putrefaction upon bacterial inoculation.

I might point to several pathological facts-among them Billroth's discovery of " cocco-bacteria" in closed abscesseswhich seem to support the idea that such actions, even the production of bacteroid forms, may, in living tissues, take place independently of external inoculation; nevertheless I prefer for the present to avoid the expression of either belief or disbelief in what may be termed the doctrine of selfinfection, especially since the proposition as above stated is theoretical only, and the phenomenon itself must be quite exceptional. But in a practical point of view the subject is of great importance; it is one that camnot be decided by theoretical arguments, nor even by the behaviour of such lifeless fluids as form the subject of mere physical experiment. The question as to whether tissues and fluids still forming part of the living body, but exposed to the air, are or are not capable of undergoing certain ferment-like changes leading to inflammatory evils, if that air be deprived of living bacteroid germs, can only be determined by direct experiment on the living human body itself. As a contribution to the number of such experiments-only feasible in the operating theatre-I offer a list of all the operations performed by me under antiseptic conditions at the Charing-cross Hospital.

\section{TABLe of ANTISEPtic Operitions in THE yeAR 1877.}

\section{Description.}

1. Middle third of thigh ...

3. Lower third of leg $\quad \ldots$

$5 . \quad$, ",

6. Above malleoli

7. Chopart's amputa...

8. Pirogoff's amputation ...

Description.

Initials.

B. W. .

A. C.

J. T.

i. $\mathrm{V}$...

A. B. ..

T. T. $\cdots$

J. $\mathrm{C}$.
Amputations.

Date of Date of

Operation. Healing.

April 19th ... April 28th ... Stump sound and hard on May 11 th.

Aug. 24th ... Sept. 2nd ... Stump quite hard on Sept. 12th.

March 21st... April 2nd ... Stump hard on April 17th.

Aug. 9th ... Aug. 26th ... Stump hard on Sept. 20th.

May 3rd $\ldots$ May 12th ... Stump hard on May 18th.

Aug. 31st ... Sept. 8th ... Stump hard immediately.

Nov. 11th ... Nov. 18th ... F ) Flaps washed with a 5 per cent. solution of

Aug. 24th ... Sept. 4th ... $\}$ carbolic acid, and dressed with terebene.

\section{Excision of Joints.}

Date of Date of
Operation. Healing.
9. Of knee $\ldots \begin{array}{lllllll}\ldots & \ldots & \ldots & \ldots & \text { H. E. .. } & \text { Dec. 16th } \ldots & \text { Jan. } 10\end{array}$

10.

11

11

$\begin{array}{llllll} & \ldots & \ldots & \ldots & \ldots & \ldots \\ \text { If ankle } \ldots & \ldots & \ldots & \ldots & \ldots\end{array}$

S. H. .

Jan. 10 th

April 5th

A. S. $\cdots$ Feb. 26 th

April 2:8rel ...

March 15 th..
Remaiks.

Bone appeared to join by immediate mion, as the synostosis was formed, on Jan. 16th.

Firm symostosis in May.

Firm tibrous bond.

Wommd looked well for ten days, then inflamed; death from tubercular meningitis. 